\title{
A poética da história: Letícia Pumar e a produção artística como pesquisa
}

\section{Pedro Hussak}

PROFESSOR DO DEPARTAMENTO DE FILOSOFIA DA UFRJ

Recortar é um ato tipicamente infantil. Trata-se de um gesto que contém sempre uma inquietação. Quem corta, corta porque incomoda-se com o que está constituído, formado, totalizado em uma unidade supostamente harmônica. Cortar significa rejeitar o "feito", o "dado" para recolocar ali um horizonte de possibilidade: "um" deve tornar-se "dois", ou mais.... Os fragmentos cortados podem sempre ser recombinados a partir de diversas montagens e remontagens. Por isso, cortar significa, no seu sentido mais profundo, uma experiência, ou seja, o conhecimento (entia) de algo fora (ex) do limite (peri). Nesse sentido, experimentar-cortar consiste em percorrer caminhos ainda não trilhados, viajar por novos países e paisagens.

Movido por inquietações, o trabalho da artista Letícia Pumar é atravessado pelo gesto de cortar. Ela recorta livros, fotografias, telas de pintura, em um movimento violento de separação, mas que busca sempre uma recomposição que, ao contrário do que é comumente associado como o que se segue ao ato de "cortar", não vem do ato de "colar" o que fora cortado. Letícia não "cola", mas "costura" o que foi inicialmente separado. Assim, se há um novo gesto no sentido de restaurar uma unidade cindida, trata-se de uma unidade fragilmente constituída a partir da costura dos elementos antes separados de modo que o todo 
inicial nunca é refeito na sua completude, mas reconstituído fragilmente em uma amarração. Essa costura faz-se por fitas que perpassam os cortes, como a sutura de uma ferida que permanece como uma cicatriz.

Mas o que leva Letícia a cortar? Ela mesma responde: "o desejo corta e borda". O desejo, assim ensina a psicanálise, é motor da vida, o que leva o sujeito a realizar e realizar-se. Cortando e bordando, ele desestabiliza o que está estabelecido e propóe uma vida mais rica em possibilidades.

Foi o desejo que levou a jovem pesquisadora em história das ciências, que na época fazia estágio "sanduíche” de seu doutorado na Fundação Oswaldo Cruz, a questionar os métodos e procedimentos da historiografia. Tal questionamento nasceu do encontro com o Atlas Mnemosyne de Aby Warburg, graças à exposição Nouvelles histoires de fantômes, com curadoria de Georges Didi-Huberman e Arno Gisinger, no Palais de Tokio, em Paris, em 20I4. Ao tomar a história da arte como história da imagem, Warburg propunha novas formas e procedimentos de abordar os métodos de pesquisa. Um conjunto de painéis nos quais ele operava, a partir de temas recorrentes da história da arte, uma montagem de fotografias, por meio da qual ele relacionava expressóes culturais de diferentes contextos espaço-temporais. A montagem desses painéis também era a ocasião para que ele desse suas aulas, verdadeiras performances que visavam ao esclarecimento das temáticas. ${ }^{I}$ Nessas aulas, Warburg modificava a posição das imagens, propondo novas formas de relação entre elas, o que proporcionava novos questionamentos e abordagens, colocando o conhecimento em movimento. Tomado a história da arte e da cultura ao mesmo tempo artística e cientificamente, Warburg trabalha em uma zona não determinada entre ambas esferas, a fim de mostrar em que medida o processo artístico poderia colaborar, para enriquecer os procedimentos científicos.

O encontro com o Atlas foi o motivo para uma transformação na historiadora duplamente envolvida pelas questóes do método científico: por um lado, como

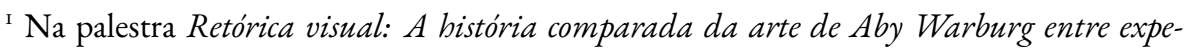
rimentação cientifica e artistica (Visuelle Rhetorik Aby Warburgs vergleichende Kunstgeschichte zwischen wissenschaftlichem Atlas und künstlerischem Experiment), proferida no MAC-Niteroi, dia 3 de junho de 20I3, o professor de história da arte da Universidade de Hamburgo e diretor da Casa Warburg, Uwe Fleckner, tratou desse tema a propósito das aulas de Aby Warburg, a partir dos painéis que compóem o Atlas. 
pesquisadora, ela estava imbuída dos procedimentos da pesquisa historiográfica, particularmente nos procedimentos para lidar com fontes primárias; por outro, na própria relação com o objeto que ela estuda, nomeadamente a história da ciência no Brasil. A questão que lhe acomete é pensar em que medida os procedimentos estéticos podem justamente operar no seu trabalho como historiadora.

Portanto, a novidade no seu percurso não está propriamente no fato de promover uma aproximação entre arte e ciência, pois no amplo universo da arte contemporânea, encontramos diversas obras que propõem essa relação. A esse respeito, muitas obras e procedimentos artísticos poderiam ser citados: formas de classificação que escapam às regras científicas ou então obras que propõem cartografias poéticas, mapas que podem ser produzidos através de uma relação com o espaço não-geometrizante, mas afetivo-simbólica. Letícia, por sua vez, apresenta uma pretensão que ultrapassa a mera reconfiguração de procedimentos científicos pela arte na medida em que almeja contribuir não apenas para esse campo, como também para o da ciência. Em outras palavras, ela não deixou de ser historiadora para tornar-se artista, mas optou por trabalhar a pesquisa em história como artista.

Disso nasce uma reflexão sobre o próprio trabalho em arquivo que, como bem assevera Jacques Derrida, consiste basicamente em uma relação de poder: as formas de classificação implicam na construção de hierarquias que definem ordens de importância, pois quem detém o poder do arquivo, detém igualmente o poder de mostrar e o de esconder. ${ }^{2}$ Nessa linha de raciocínio, uma política do arquivo deveria operar nessa tensão entre o oculto e o visível para permitir que a memória apareça não como uma totalidade, mas através de vestígios, traços, fragmentos cuja fragilidade revela a força de um acontecimento.

Notadamente, para a artista, trata-se de colocar em jogo o estatuto da imagem na pesquisa historiográfica, pois ela frequentemente é tomada ou como um documento no sentido de registrar algo ou como um elemento que serve para "ilustrar" a pesquisa. Em ambos os casos, toma-se a imagem a partir de sua visualidade;

2 "É bem verdade que o conceito de arquivo abriga em si mesmo essa memória do nome arkhê. Mas também se conserva ao abrigo desta memória que ele abriga: é o mesmo que dizer que a esquece”. DERRIDA, Jacques. Mal de arquivo: impressão freudiana. Tradução de Claudia de Moraes Rego. Rio de Janeiro, Relume Dumará, 20oI, p. I2. 
busca-se na imagem de algo que ela possa mostrar para "enriquecer" a pesquisa. No entanto, laborar a imagem para que ela revele algo sobre a memória requer uma operação paradoxal: a imagem deve revelar algo não pelo o que ela mostra, mas ao contrário pelo que ela não mostra, ao menos não no que ela não mostra imediatamente. A imagem toca o real, assim argumenta Georges Didi-Huberman, por meio dos vestígios, traços, fragmentos que só podem aparecer na medida em que se trabalha a imagem, por meio de uma montagem. ${ }^{3}$

Trabalhar a imagem, a partir de arquivos, foi o que ela fez na exposição Rural em imagens: para além dos clichês, em 2018, resultado de um trabalho com alunos do curso de graduação de história da Universidade Federal Rural do Rio de Janeiro, no qual são conjugadas fotos antigas encontradas no arquivo da universidade com fotografias retiradas pelos próprios alunos no campus da universidade. Trabalhando sem hierarquia entre o passado e o presente, Letícia e seus alunos produzem imagens, criando faixas intercaladas entre uma foto antiga e uma nova, fazendo uma confusão intencional na percepção da figura-fundo. ${ }^{4}$

No entanto, a produção de Letícia não consiste (apenas) em associar imagens. $\mathrm{O}$ fato de que se trata de uma historiadora trabalhando artisticamente o arquivo não deve enganar sobre a base do seu processo artístico, nomeadamente a pintura. Seguindo as aulas do professor João Magalhães, na Escola de Artes Visuais do Parque Lage, no Rio de Janeiro, a partir de 20I6, ela rapidamente encontra um caminho próprio uma vez que escolhe trabalhar com várias técnicas conjuntamente. Ao associar a pintura a dois outros elementos, a fotografia e o texto, a artista elabora seu trabalho agregando vários elementos à pintura que, assim, não funciona autonomamente, mas em relação a outros elementos. Por isso, não é difícil supor que suas pinceladas entram na lógica da montagem.

Ela trabalha a pintura como um processo de intervenção sobre outros suportes, visando ao tensionamento, por meio de um gesto violento, do seu sentido

3 "O próprio do arquivo é a lacuna, sua natureza lacunar. Mas, frequentemente, as lacunas são resultado de censuras deliberadas ou inconscientes, de destruiçóes, de agressões, de autos de fé. O arquivo é cinza, não só pelo tempo que passa, como pelas cinzas de tudo aquilo que o rodeava e que ardeu”. DIDI-HUBERMAN, Georges. “Quando as imagens tocam o real”. Tradução de Patrícia Carmello e Vera Casa Nova. In: PÓS: Revista do Programa de Pós-graduação em Artes da Escola de Belas Artes da UFMG, v. 2, n. 4 p. 204-2019, nov. 2012.

${ }^{4}$ Sobre a exposição Rural em imagens: para além dos clichês, cf. HUSSAK, Pedro; OLIVEIRA, Flávia. Imagem-clichê, imagem-abertura, o texto de apresentação da exposição. 


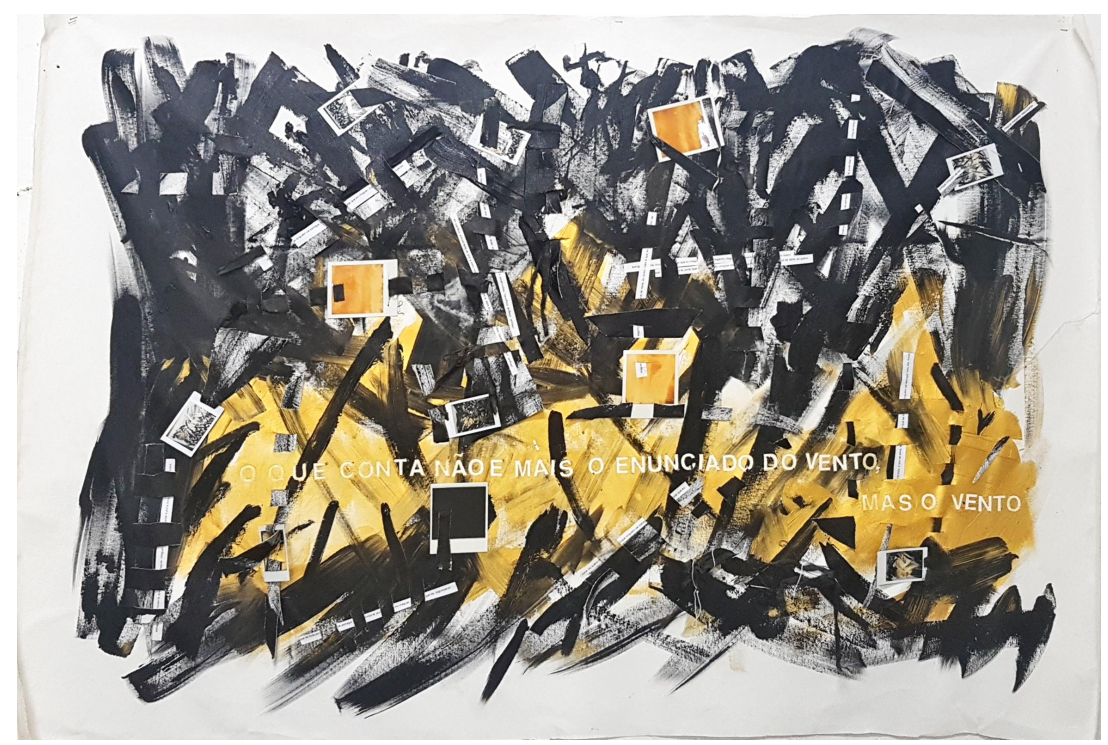

Figura I - Sem título, 2017. Acrílica, tecido, fotografia e papel sobre tela sem chassi. I,65 x I,17 $\mathrm{cm}$.

original. Por isso, em seus primeiros trabalhos, ela pinta sobre jornal usando uma pincelada "expressionista" na qual sobressai-se a tinta preta. Nesse trabalho, já se percebe claramente essa relação supramencionada entre a pintura, a fotografia e o texto, que será uma constante nas suas obras posteriores, particularmente as intervenções sobre livros, como veremos adiante.

Essa relação surge no trabalho Sem título de 2017 (Figura I), em que sobre um tecido, Letícia faz pinceladas em preto e amarelo, pinceladas fortes que são como vetores apontando para vários lados. Também os cortes no tecido são vetores através dos quais perpassam fitas entrelaçando-os. Nessas fitas, é possível ler trechos de letras da cantora funk Ludmilla, como a de Cheguei, de 2oi6. Assim, o trabalho perfaz a conexão entre o texto e a trama. Dependuradas sobre tela, polaroides da própria pintura, um registro do processo da pintura que é incorporado ao trabalho final.

Sobre o amarelo na parte inferior do tecido, lê-se: "O que conta não é mais 
o enunciado do vento, mas o vento", 5 uma frase de Georges Bataille ${ }^{6}$ que diz respeito ao problema da comunicação. Crítico do racionalismo, o escritor francês defende que a comunicação real não acontece por meio de enunciados frios, mas sobretudo através de um elemento estético, sensível. A percepção direta do mundo, o contato com a materialidade das coisas do mundo como uma alternativa ao trabalho dos conceitos da ciência e da Razão.

Se, como foi dito, Letícia, em seu trabalho artístico, pretende dar uma contribuição para a pesquisa historiográfica, essa ocorre justamente em trazer à tona o elemento sensível do trabalho historiográfico tão esquecido por pesquisadores impregnados de "métodos" e "procedimentos". A pesquisa historiográfica faz-se, entre outras coisas, lidando com documentos, portanto com uma materialidade que muitas vezes é esquecida ou tomada como irrelevante, mas cuja importância revela como atua o elemento sensível na produção do conhecimento historiográfico.

No entanto, não apenas por expor a materialidade do trabalho, como também por acentuar a dimensão do "eros do conhecimento" que Letícia quer destacar a relevância da sensibilidade para trabalho científico. Se é verdade que uma análise para ser reputada como "séria" e "rigorosa”, precisa afastar os "desejos" e "paixóes" e ater-se à frieza dos argumentos racionais, é igualmente verdade que para que se conheça, é necessário primeiro a "paixão" e o "desejo" pelo conhecimento. O desejo por aquilo que se estuda é o que deve mover o pesquisador em seu processo. Letícia diz-nos que "o desejo corta na borda". O desejo pela pesquisa implica em trabalhar nas margens, tentando descobrir os detalhes, as sutilezas, as singularidades dos seus objetos de estudo.

Selecionada no edital Novissimos (Figura 2), ela expõe uma série com três trabalhos, intitulada Operando cortes em uma exposição coletiva, com curadoria de Cesar Kiraly, na galeria do IBEU, no Rio de Janeiro, entre julho e agosto de 20I8. A relação fotografia, pintura, texto acontece não apenas nas próprias obras, como também na montagem da exposição dos trabalhos. Junto a duas obras, Livro-obra em dois volumes e Sem título, está um poema, intitulado Operando cortes: poema-ato.

s “ce qui compte n'est plus l'énoncé du vent, c'est le vent” (BATAILLE, Georges. L'expérience intérieure. Tel. Paris, Gallimard, 2009, p. 25.)

${ }^{6}$ Id., ibid. 


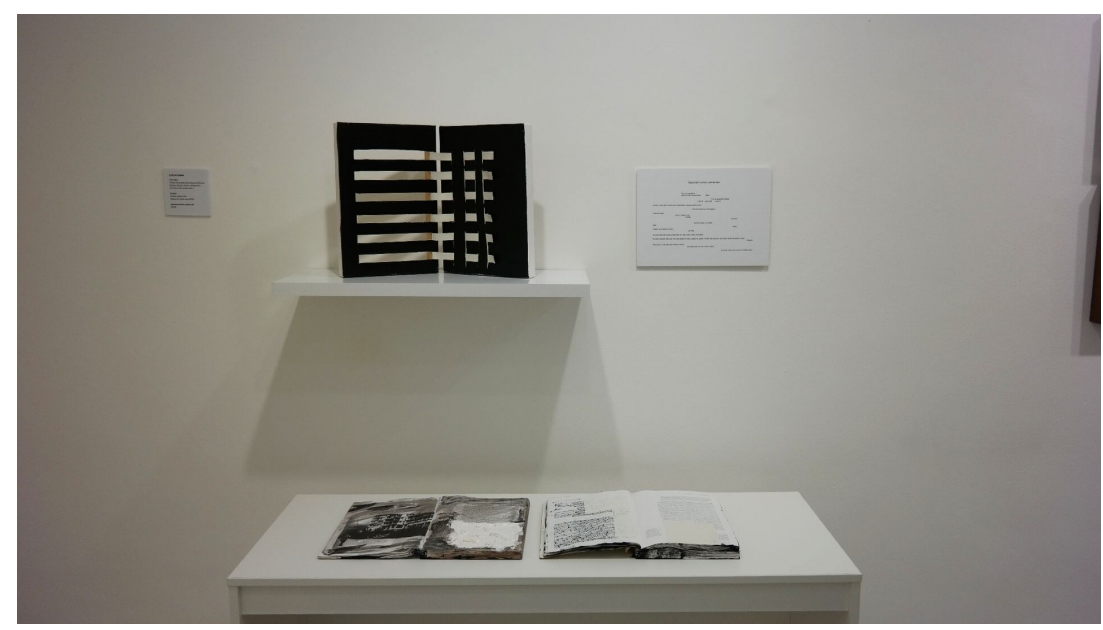

Figura 2 - Exposição Novissimos, 20I8. Galeria IBEU, Rio de Janeiro.

Nos dois volumes de Livro-obra (Figura 3 e 4), Letícia coloca em jogo sua própria trajetória como pesquisadora em história da ciência e expressa sua inquietação como o modo pelo qual ela realizava esse processo. Ela diz-nos que o trabalho

diz respeito a publicações da Revista história, saúde, ciência - Manguinhos que sofreram intervenções pictóricas. Utiliza-se a publicação como suporte para um trabalho de pintura e colagem, apropriandose dos elementos de escrita e articulando diferentes linguagens. ${ }^{7}$

Trata-se de uma intervenção sobre uma revista científica da Fundação Oswaldo Cruz - instituição onde ela cursou o mestrado e o doutorado em história da ciência -, na qual ela mesma contribuíra em outros números com um artigo e uma resenha e como parecerista. Ela faz uma série de operaçóes: pinta sobre os artigos com uma tinta preta com pinceladas fortes que lhe são características; apaga determinadas palavras com a mesma tinta, construindo assim um novo texto; apaga duas páginas com tinta branca, deixando apenas uma frase; faz cortes

${ }^{7}$ Material enviado pela artista para a seleção do Edital Novissimos, 20I8. IBEU. 


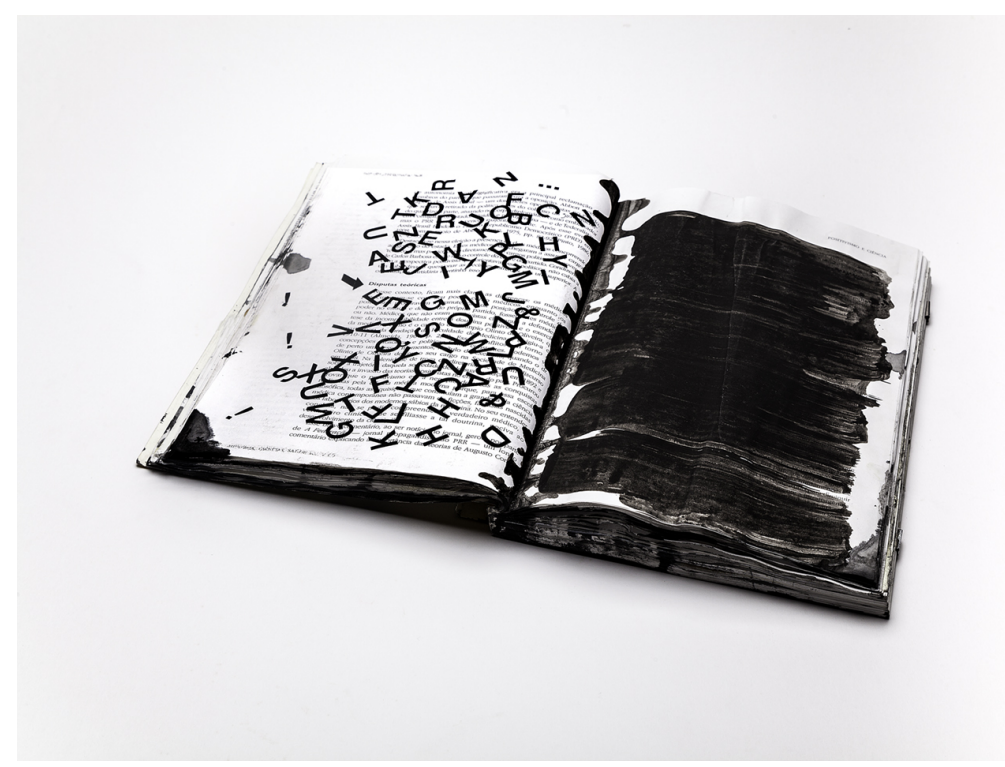

Figura 3: Livro-obra, 2017. Técnica mista sobre dois volumes da revista História, saúde, ciência Manguinhos. 34 × $26 \mathrm{~cm}$ (cada).

em diagonal no mesmo estilo em que ela corta suas telas; recorta os textos e cola novamente, reescrevendo assim os artigos; insere novos textos, dialogando com o título de um dos artigos.

Letícia profana este que é um espaço fundamental de todo o sistema da pesquisa científica - a difusão dos resultados das pesquisas. Intervindo na apresentação visual da revista, ela vale-se da sensibilidade não apenas para estabelecer um diálogo com o próprio saber exposto ali, como também para deixar surgir outras possibilidades, outros elementos que podem esconder-se atrás da rigidez dos artigos publicados. As operaçóes de Letícia intervêm nessa rigidez, a fim de propor uma forma de pesquisa que aceite a instabilidade desse objeto de estudo que é a história. Sim, porque o passado não é um dado fixo, imóvel. Como diria Walter Benjamin, quanto mais o historiador, tal qual um arqueólogo, escava o passado, mais camadas vão surgindo dessa pesquisa:

Quem pretende aproximar-se do próprio passado enterrado deve comportar-se como um homem que escava. Sobretudo, ele não deve 


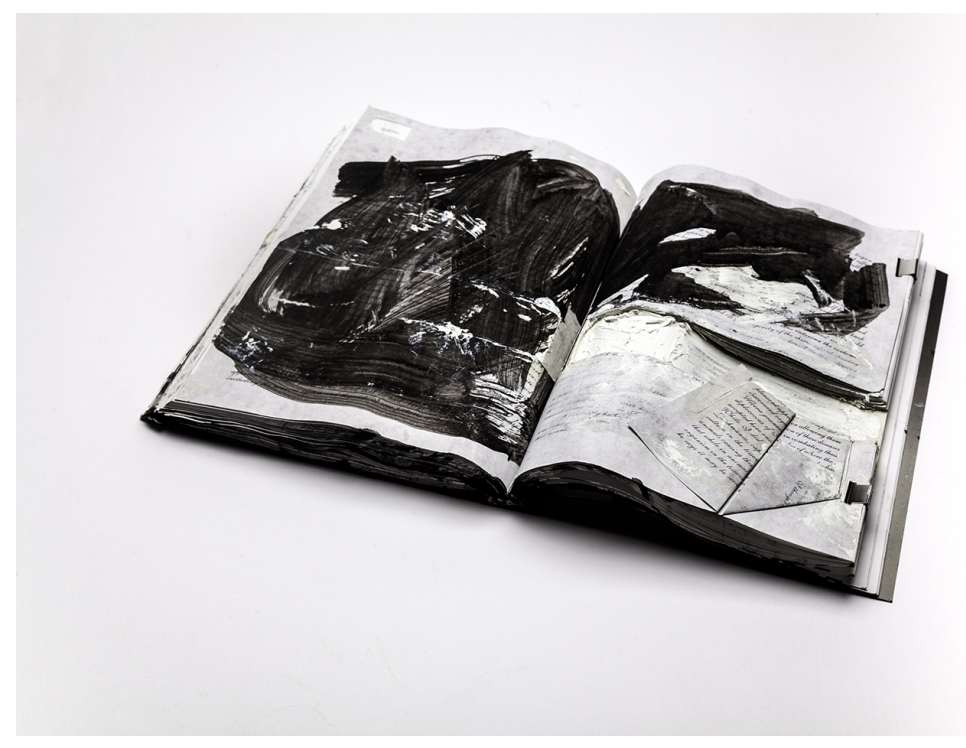

Figura 4: Livro-obra, 2017. Técnica mista sobre dois volumes da revista História, saúde, ciência Manguinhos. 34 × $26 \mathrm{~cm}$ (cada).

temer retornar sempre novamente à mesma matéria [Sachverbalt]; espalhá-la como se espalha a terra para revolvê-la, como se revolve a terra. $^{8}$

Nesse sentido, introduzir o processo artístico na pesquisa historiográfica significa abrir mão de uma certa segurança que o método científico poderia oferecer. Trata-se, portanto, de aceitar o lugar da dúvida e da incerteza, a fim de que novos questionamentos sempre possam surgir, abrindo assim novas possibilidades a partir do que fora previamente construído. Nesse sentido, Letícia propóe que esse conhecimento seja colocado em movimento de modo a lutar contra toda sua petrificação e mumificação que, por sua vez, é a base de toda arrogância daquele que se atribui uma autoridade supostamente adquirida graças ao "conhecimento".

${ }^{8}$ BENJAMIN, Walter. "Escavar e lembrar". In: TIEDEMANN, Rolf; SCHWEPPENHÄUSER, Hermann. (Orgs.). Walter Benjamin - Gesammelte Schriften, v. VI. Fragmente, Autobiographische Schriften, Frankfurt am Main, 1984, p. 486. Tradução nossa. 


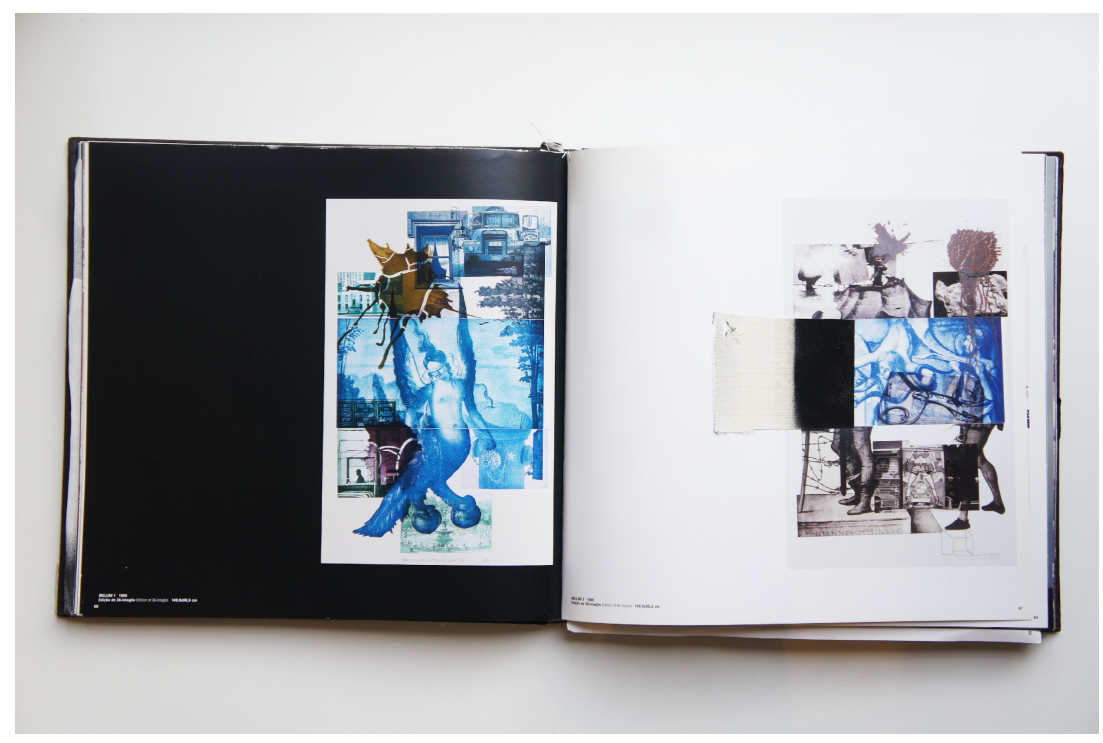

Figura 5: Rauschenberg, 2018 (Técnica mista sobre livro de arte, $62 \times 29 \mathrm{~cm}$ )

Ao reconfigurar as operações e funções que organizam a apresentação da pesquisa historiográfica, a artista trabalha a poética da apresentação do saber histórico, e nisso entra em jogo o princípio da montagem com o qual a artista dialoga com o saber antes realizado. Essa dimensão dialógica naturalmente pode ser sempre atualizada em novos diálogos, dando uma dimensão que em princípio poderia ser considerada absurda: que o trabalho de pesquisa em historiografia seja infinito.

A intervenção em livros será uma constante no trabalho da artista seja na intervenção em um livro do autor Rodrigo Naves em que ela dialoga plasticamente com as posiçôes sobre história e teoria da arte ali expostas, seja nas interferências sobre um livro de arte de Robert Rauschenberg após uma visita ao seu arquivo em Nova Iorque cujo resultado não foi a publicação de artigos científicos, mas um trabalho artístico (Figura 5) a partir da obra do artista estadunidense. ${ }^{9}$

${ }^{9}$ A partir da pesquisa nos arquivos de Rauschenberg, Letícia fez também um segundo trabalho usando como suporte um caderno que funcionou como um "diário de pesquisa" com 
Intervenção em um livro também aparece no trabalho, que embora estivesse no projeto inicial não entrou na exposição do IBEU, chamado Hoje é dia de vermelho (os sentidos da história) (Figura 6), em que "uma tela pintada de vermelho é utilizada para operar cortes e costuras num livro de história". ${ }^{\circ}$ Letícia secciona as duas primeiras páginas do livro, criando caminhos através dos quais fitas vermelhas atravessam, criando um jogo "dentro-fora" entre o branco das páginas e o vermelho das fitas que ultrapassam o limite das páginas, saindo do espaço delimitado do livro. As fitas são vetores que vão em várias direções, desafiando o título do livro $O$ sentido da história, no singular. Sensivelmente, ela propõe um debate teórico com o autor do livro: em vez de um sentido único, teleológico, da história, os vetores provocam o espectador a pensar nos sentidos da história, no plural. A história, assim, para Letícia, não é feita de uma temporalidade homogênea, mas de várias temporalidades que se entrecruzam e apontam para diferentes direçóes. Ao apresentar o trabalho nas redes sociais a artista diz: "Em tempos sombrios, o vermelho é um gesto, um gesto que vem de longe".

Chama a atenção a recuperação do vermelho, tão importante para a arte contemporânea brasileira quer pensemos em Cildo Meireles ou em Tunga, por exemplo. O jogo entre o vermelho e o branco vai aparecer em outros trabalhos, feitos em um registro mais acentuadamente ligado à pintura: em uma tela redonda vermelha monocromática, cortes à la Fontana, mas que indicam os mesmos vetores que apontam para vários sentidos; uma tela totalmente branca retangular e exposta de forma vertical em que uma fita vermelha perpassa em curva os cortes; uma tela quadrada vermelha, com muitos cortes na qual perpassa uma fita branca; e finalmente uma tela totalmente branca quadrada na qual a fita que perpassa os cortes está no canto direito. ${ }^{\text {II }}$

No entanto, se essa relação com a pintura pode sugerir uma adesão a um abstracionismo formalista, essa produção reflete, por outro lado, as preocupações da artista em torno do problema da pesquisa historiográfica. Assim, as pinturas de fotos, colagens, anotações, etc. Este último foi exposto no Ateliê Oriente. (Rauschenberg (short stories) na exposição coletiva Livro inventado II - Gestos experimentais, organizado por Marcos Bonisson, na Galeria Oriente, Glória, Rio de Janeiro, nov. 20I8).

Io Material enviado pela artista para a seleção do Edital Novíssimos 2018. IBEU.

${ }^{\text {II }}$ Esse último foi exposto na exposição coletiva Patifaria!, na Escola de Belas Artes (UFRJ), em 20I9, e no Espaço Poético Titocar, em 2020. 


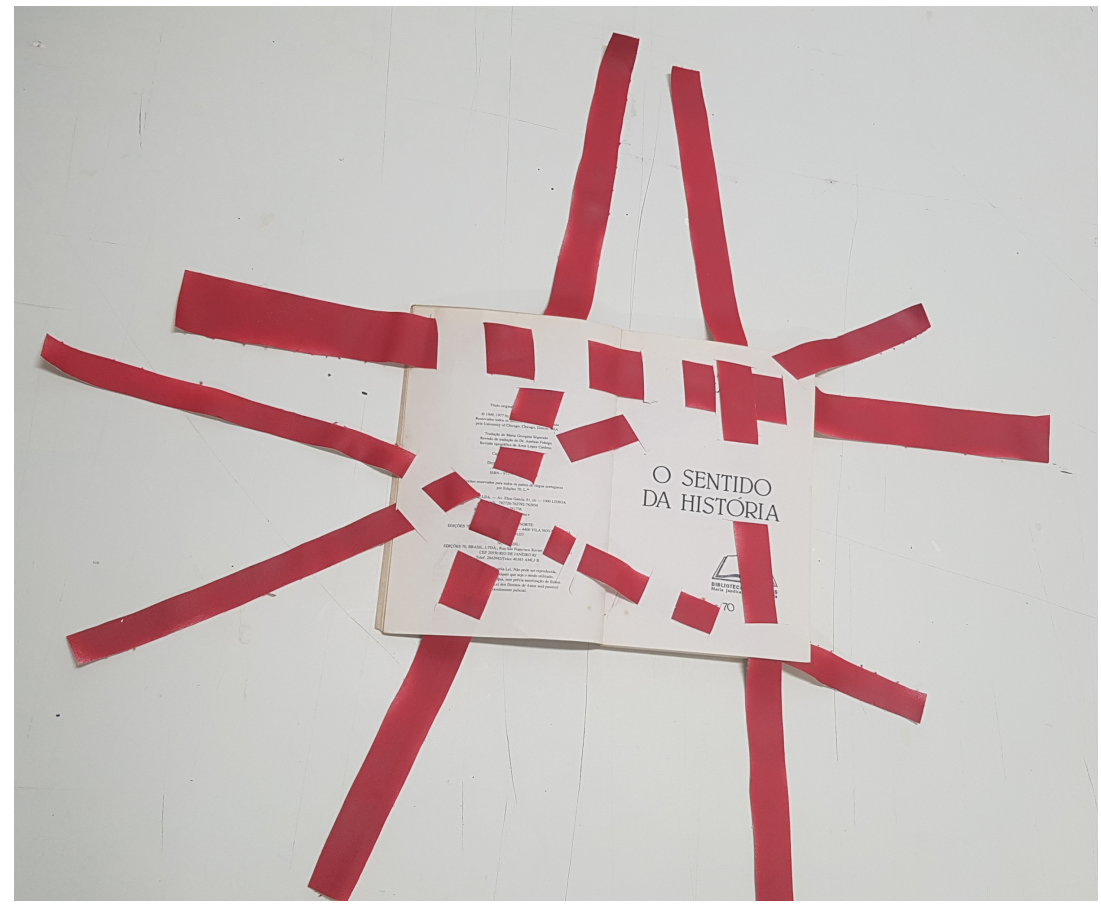

Figura 6: Hoje é dia de vermelho (Os sentidos da história), 20I8. Acrílica sobre tela e tela sobre livro. Dimensões variáveis.

Letícia devem ser lidas sobretudo a partir das intervenções nos livros que buscam problematizar os sentidos da história.

Por isso, a terceira obra da exposição no IBEU, Sem título (2018), que "sublinha as potencialidades plásticas dos elementos da escrita" ${ }^{12} \mathrm{em}$ princípio pode induzir a uma relação com o concretismo. No entanto, ela busca estabelecer uma relação entre imagem e palavra tão cara para a artista. Duas telas retangulares, na vertical, são colocadas lado a lado: na tela da direita são feitos cortes que retiram tiras na horizontal que penetram os cortes feitos na outra tela, estabelecendo aqui um jogo entre o preto e o branco. As fitas fazem a "costura" entre uma tela e outra, estabelecendo uma união precária entre ambas.

\footnotetext{
${ }^{\text {I2 }}$ Material enviado pela artista para a seleção do Edital Novissimos, 2018 - IBEU.
} 


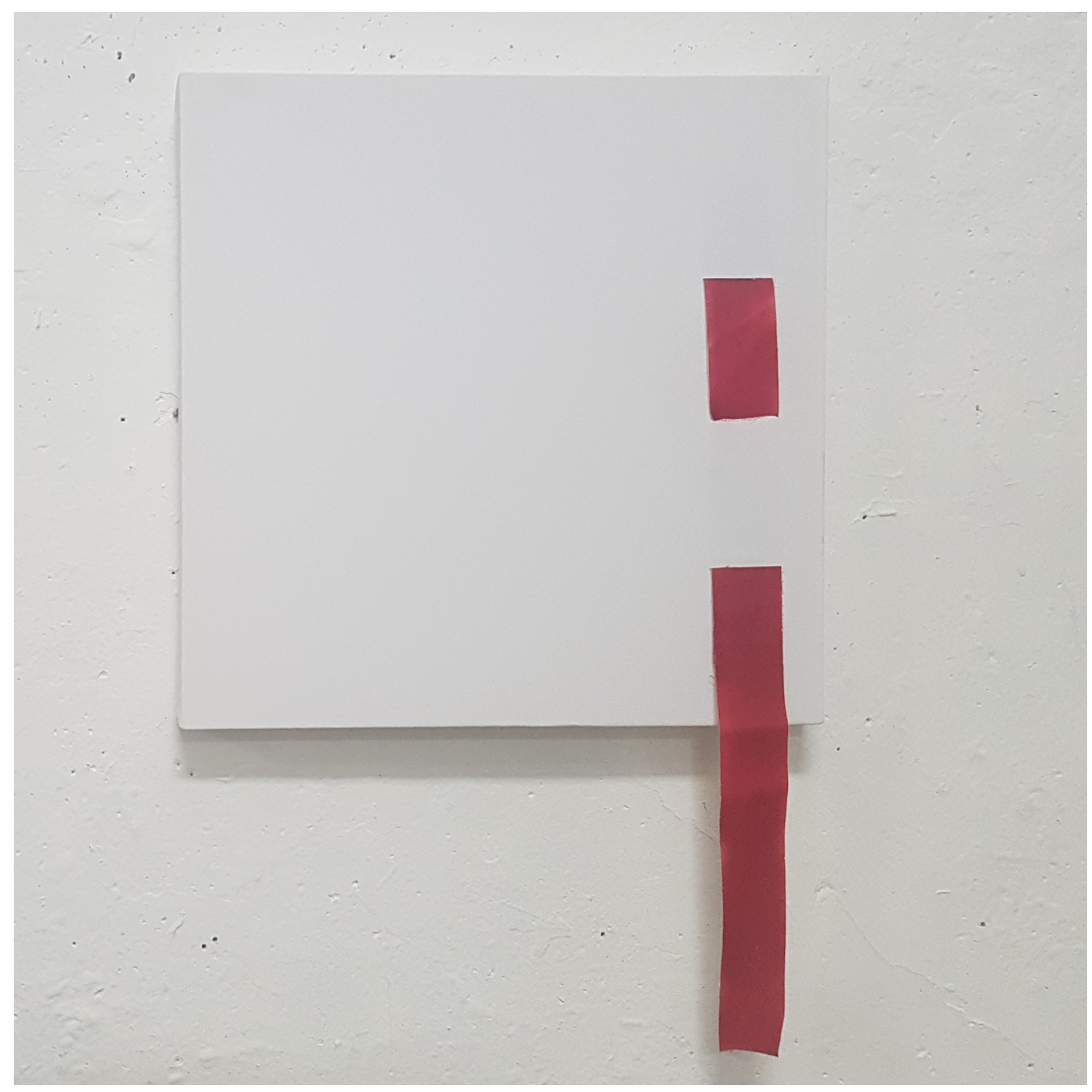

Figura 7: Desejo, 2019. Acrílica e tela sobre tela. 40 x $40 \mathrm{~cm}$.

Esse trabalho dialoga imediatamente com o poema Operando cortes: poemaato em que ela reflete sobre as questóes que são igualmente pensadas imageticamente. Trata-se de um poema em que ela "corta" citaçóes de outros autores e as "costura" com frases e formulações dela mesma. Ali pode-se ler: "vive de experiência sensível e não de explicação lógica e que vive de experiência lógica e não de explicação sensível”; diz também que o "desejo corta e borda" ou ainda que "parece que é o não saber que costura o tempo".

Escrever poesias, para Letícia, não é, portanto, uma atividade distanciada do seu processo como artista plástica. Muito pelo contrário, o poema, a imagem, 


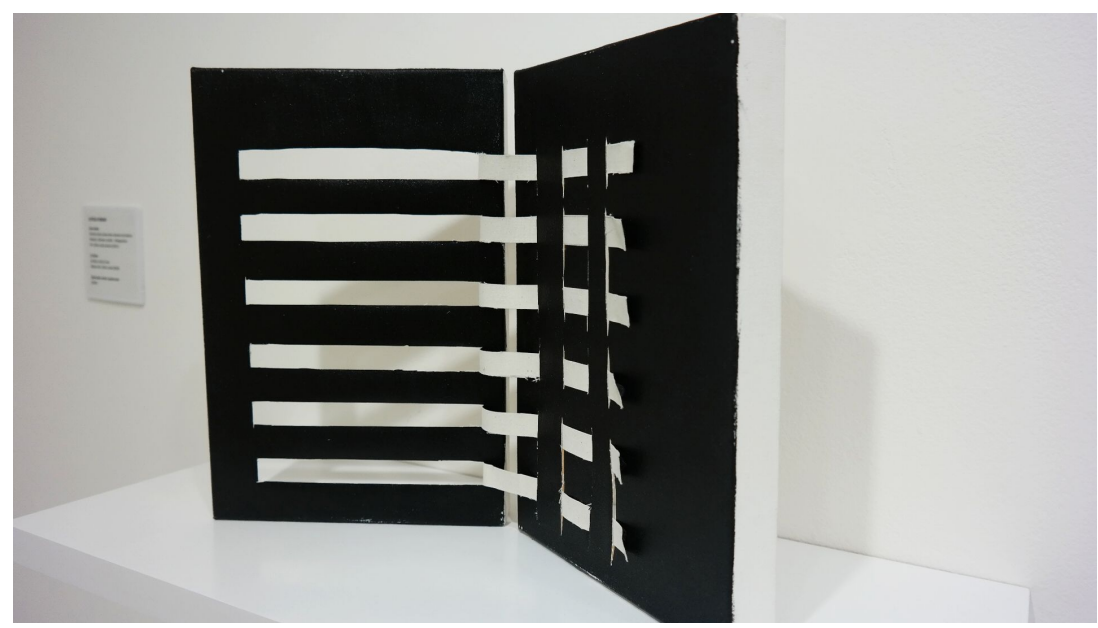

Figura 8: Sem título, 20I8. Acrílica e tela sobre tela, díptico. 30 x $20 \mathrm{~cm}$ (cada).

a pintura estão entrelaçados na construção de uma poética. Desafiando lugares estabelecidos, ela coloca-se entre a pesquisadora, a artista plástica e a poeta. Esse lugar indefinido, por sua vez, é o que dá a potência criativa de uma realizadora que almeja encontrar novas possibilidades no campo da historiografia.

Pintura, fotografia, texto, meios pelos quais Letícia pensa um problema e propóe um diálogo com o modo de apresentação tradicional do conhecimento. Trata-se, portanto, de um trabalho que só se compreende por meio de um tensionamento, o qual pode ser bastante frutífero para a produção do saber.

A exposição Novissimos permitiu o desabrochar de uma artista talentosa que apesar de jovem apresenta plasticamente seus questionamentos já com grande maturidade. No entanto, há ainda um grande caminho a ser percorrido que vai render ainda muitos frutos e abrir diálogos sobre o sentido da pesquisa historiográfica. Fica o desejo de que esses questionamentos tenham repercussão não apenas no campo da arte, mas também na esfera acadêmica e que os centros de pesquisa em História possam se abrir para novas possibilidades de pesquisa, tal como propóe Letícia Pumar. 


\section{Referências bibliográficas}

BATAILLE, Georges. L'expérience intérieure. Tel. Paris: Gallimard, 2009. BENJAMIN, Walter. "Escavar e lembrar”. In: TIEDEMANN, Rolf \& SCHWEPPENHÄUSER, Hermann. (Orgs.). Walter Benjamin - Gesammelte Schriften, v. VI. Fragmente, Autobiographische Schriften. Frankfurt am Main, 1984. DERRIDA, Jacques. Mal de arquivo: impressão freudiana. Tradução de Claudia de Moraes Rego. Rio de Janeiro: Relume Dumará, 20oI.

DIDI-HUBERMAN, Georges. "Quando as imagens tocam o real”. Tradução de Patrícia Carmello e Vera Casa Nova. In: PÓS Revista do Programa de Pósgraduação em Artes da Escola de Belas-Artes da UFMG, v. 2, n. 4, p. 204-219, nov. 2012.

\section{g}

Resumo: Este artigo consiste em uma análise do trabalho da artista plástica Letícia Pumar, ressaltando como ele reflete em grande medida a sua própria trajetória. Ao tomar contato com o Atlas Mnemosyne de Aby Warburg, cujo procedimento situa-se entre a ciência e a arte, a pesquisadora em história da ciência passa a incorporar procedimentos do campo artístico para a pesquisa historiográfica. Trata-se de acentuar os elementos sensíveis da pesquisa histográfica, como a materialidade dos documentos e o trabalho com as imagens a fim de elaborar uma poética da historiografia, ou seja, outras possibilidades de apresentação dos resultados de uma pesquisa.

Palavras-chave: pesquisa; historiografia; arte contemporânea; Atlas.
Abstract: This article consists of an analysis of the work of the artist Letícia Pumar, highlighting how it largely reflects her own trajectory. Upon contact with Aby Warburg's Atlas Mnemosyne, whose procedure lies between science and art, the researcher in the History of Science begins to incorporate procedures from the artistic field to historiographic research. It is a question of emphasizing the sensitive elements of histographic research, such as the materiality of documents and the work with images in order to elaborate a poetics of historiography, that is, other possibilities of presentation of the results of a research.

KEYWORDS: research; historiography; contemporary art; Atlas. 